\title{
SPECIES PLURALISM DOES NOT IMPLY SPECIES ELIMINATIVISM
}

\author{
Ingo Brigandt ${ }^{\dagger *}$
}

January 9, 2002

5000 words including footnotes and references

${ }^{\dagger}$ Department of History and Philosophy of Science

University of Pittsburgh

1017 Cathedral of Learning

Pittsburgh, PA 15260

E-mail: inb1@pitt.edu

*I would like to thank Paul Griffiths, Jim Lennox, Sandy Mitchell, Marc Ereshefsky, Alan Love, and Jim Tabery for helpful comments on this paper. 


\begin{abstract}
Marc Ereshefsky argues that pluralism about species suggests that the species concept is not theoretically useful. It is to be abandoned in favor of several concrete species concepts that denote real categories. While accepting species pluralism, the present paper rejects eliminativism about the species category. Based on the idea that the species concept is a socalled investigative kind concept, it is argued that the species concept is important and that it is possible to make sense of a general species concept despite the existence of different concrete species concepts.
\end{abstract}


1. Introduction. Biologists are currently confronted with a plethora of species concepts. Philosophers and biologists have reacted differently towards this situation. Some maintain that only one species concept is fundamental to biology, and that the current debate will lead to a uniquely correct species concept (Ghiselin 1987; Hull 1987; Mayr 1987). Other authors take a pluralist approach instead; different species concept are equally legitimate and useful in classifying organisms and understanding the history of life (Dupré 1993; Kitcher 1984; Mishler and Brandon 1987; Mishler and Donoghue 1982; Rosenberg 1994; Stanford 1995). Marc Ereshefsky not only defends pluralism, but claims that pluralism has a bold consequence: the species concept is not theoretically useful. While the different species categories defined by various concrete species concepts (such as the biological species concept) are real, this does not hold for the category referred to by the general term 'species'. Ereshefsky calls his radical account 'eliminative pluralism'. The subject of my paper is a critical discussion of this position. While largely accepting pluralism and Ereshefsky's arguments for it, I try to show that we need not be forced to accept his eliminativist conclusion. The species concept is a useful and theoretically important concept in biology. I argue that we can make sense of the general species concept despite the existence of various concrete species concepts and definitions.

2. Ereshefsky's Eliminative Pluralism. The eliminativist approach to the species concept is most clearly expressed and defended in Ereshefsky 1992 and 1998. The basis for this position 
is Ereshefsky's account of pluralism, which is ontological. The fact that any single organism can be classified into different species categories is a real feature of the world of organisms. Current theories of phylogeny and evolution describe different mechanisms that shape the history and cohesion of organisms. On Ereshefsky's account, there are three different, real forces in evolution, which partition the tree of life into different units. Interbreeding creates certain units in accordance with interbreeding accounts of species (such as the biological species concept). Phylogenetic accounts, on the other hand, pick out units characterized by common descent. And the units on which ecological accounts of species focus are brought about by ecological selection. Ereshefsky proposes three different (concrete) species concepts corresponding to these forces: 'biospecies', 'phylospecies', and 'ecospecies'.

While these three concepts refer to real categories, Ereshefsky's next step consists in claiming that there is no (general) species category. The term 'species' should be eliminated and replaced by a plurality of more useful terms (1992, 681). In Ereshefsky 1998 this position is conceptualized as anti-realism about species. The species concept is not theoretically useful because there exists no species category. Based on his ontological account of pluralism, Ereshefsky defends this conclusion with his heterogeneity argument. His criterion for the existence of a category is that the members share some commonality that out-group members do not have. Different species concepts focus on distinct mechanisms (interbreeding, common descent, ecological selection). Therefore, taxa classified in accordance with several species concepts do not share a generating mechanism or any other important feature. Ereshefsky 
argues that there is no commonality that all different species taxa share, which distinguishes them from other kinds, in particular other taxa. In his view, this amounts to the fact that there is no species category: "there is no unified ontological category called 'species"” (1998, 113). (But the various species taxa are considered as real, apparently because the individuals belonging to such a taxon are united by the mechanism that brought this taxon about; a taxon has a unified ontological structure.) Ereshefsky addresses the possibility of giving a disjunctive definition of 'species' based on the three concrete (and real) species concepts, but argues that these kinds of definitions do not have ontological import.

3. Two Critical Questions. Ereshefsky's account has considerable plausibility; he advances a point that needs to be more fully explored. Pluralism about species is a likely option, and Ereshefsky's ontological approach supplies arguments for why the use of distinct species concepts might be necessary and useful. My reply is consistent with pluralism and largely accepts Ereshefsky's point that some concrete species concepts are based on different and relevant generative mechanisms. However, in my view this does not entail that the species concept itself is theoretically useless or should be abandoned. I start my discussion by raising two critical questions that Ereshefsky does not address. These issues frame my own discussion and position, because I think that any account of the species concept has to give some reasonable answer to them, which in turn might point to some positive aspects of retaining the species concept. 
First, Ereshefsky could interpret the current use of the term 'species' as shorthand for some concrete and legitimate species concept, or as some placeholder that needs to be filled out. But what about historical uses of the species concept? Obviously, the species concept has been important for biological theorizing. For example, the models by Lotka and Volterra give a theoretical account of the interaction between predator and prey species, and Darwin's theory of evolution by natural selection explains the emergence or preservation of new species. An account that maintains that the species concept is in fact theoretically useless has to give an interpretation of historical episodes. Ereshefsky's ontological approach admits only three distinct species categories. One could claim that in the past biologist partially referred to these categories, or that their species concept was a conflation of the biospecies, phylospecies, and ecospecies concepts. However, such a position seems to be historically unlikely. It is a strong commitment to claim that the in the past no categories different from current ones were used. Stanford (1995) argues that the reference of species concept actually changed in the course of history. In the case of the species concept we have probably to admit that this concept underwent change. Whatever the truth of the matter, Ereshefsky does not address this historical issue. I suggest that we revisit the species concept and look for an account that gives a more favorable historical interpretation of this concept than the eliminativist approach, which admits the mere term 'species' and reference to species taxa but not a general theoretically useful species concept. 
My second critical question does not deal with the historical usage of the term 'species', but rather with the current debate about species concepts. A crucial feature for Ereshefsky's position is his pluralism about species. But pluralism means that there are several species concepts, instead of only one legitimate species concept. Thus it might seem that Ereshefsky has to give us an account of why the concepts he advances are in fact species concepts, rather than being three unrelated concepts 'biospecies', 'phylospecies', and 'ecospecies'. He is not necessarily committed to do so. In any case, an answer to the question of why the different species concepts are in fact species concepts might reveal some commonality of species concepts, which could make the species concept theoretically more useful. Ereshefsky does not address this question. Dismissing the fact that we use the term 'species' for different species concepts as a "linguistic habit" without ontological import $(1998,115)$ does not give an explanation of this 'linguistic habit'. In my view, it is interesting to take a closer look at this issue. To be sure, when a term fragments it is a real question depending on the concrete situation whether the old term is useless and has to be replaced in favor of the new concepts. My point stems from that the fact that the species concept figured in former theories which were able to offer adequate explanations and that there is a real debate about the plurality of species concepts. This suggest that we should address the question of what makes a concept a species concept. Then we might uncover a more favorable interpretation of historical usages of the species concept and reveal that this concept is theoretically more important than Ereshefsky's eliminativism admits. 
4. Investigative Kind Concepts. Ereshefsky's argument against the species category has two steps. First he argues that the taxa defined by the three legitimate species concepts have no characteristic feature in common because they are defined by means of different generative mechanisms and thus have different ontological structures. Then he concludes that an alleged species category does not exist because any category needs a common feature. My reply will not reject outrightly either step of this argument. It will largely accept Ereshefsky's argument for pluralism while suggesting a different conclusion. While Ereshefsky's position is ontological, my approach is epistemic and will be called the investigative account. In a nutshell it has the following picture of the species concept. For Ereshefsky the general species concept can be nothing more than a disjunction of the three concrete species concepts. The investigative account, on the other hand, maintains that the general species concepts sets the standards for what counts as a good species concept. Namely, a concrete species concept should pick out species taxa and contribute to explaining the evolutionary and ecological behavior and properties of species. The investigative account thus addresses my second critical questions.

In Ereshefsky 1998 eliminativism is called anti-realism. However, in what follows I largely try to avoid framing my discussion in terms of realism vs. anti-realism, because realism is a delicate concept used with several meanings. Kitcher (1984) and Stanford (1995), for instance, have an understanding of species realism that appears to be different from 
Ereshefsky's. A complete discussion about the theoretical usefulness of the species concept should be based on an elaborated philosophical theory that gives a convincing account of scientific concepts and conceptual change in science. This paper is not the place to defend such a theory. For the present discussion it is sufficient to point out that any theory of concepts with the following features would give a philosophical foundation for my position on the species concept, and these features seem to be plausible constraints on any theory of concepts. An adequate theory of concepts would take a middle road between an approach that assumes that a concept fundamentally changes whenever scientific theories change (Kuhnian semantic incommensurability) and a purely causal theory of reference that assumes that a concept gets introduced and that our set of beliefs about the referent rather than the concept changes (the account of Putnam 1975). Concepts are dynamic entities, in a sense similar to theories, which change in the course of scientific investigation. They are historical entities, a current concept might be derived from a former variant, and it can reflect some aspects of the former usage. A convincing theory of scientific concepts has to take pragmatic and epistemic factors as well as the theoretical and explanatory interests that are associated with having a specific concept into account. Brigandt (n.d.a) and (n.d.b) work towards such an account..

A special type of concepts that are of interest for the present case are what I call investigative kind concepts. An investigative kind is a group of things that are presumed to belong together due to some underlying mechanism or a structural property. The idea that these entities belong to a kind might be due to some interesting similarities. Scientists perceive 
a certain pattern in nature. However, these similarities are not deemed to be what characterizes this kind. Instead, an investigative kind is specified by some non-trivial underlying feature or process that is presumed to account for the observed similarities. An investigative kind concept thus originates when a certain pattern among a class of objects is observed and it is assumed to be founded on some theoretically important, but yet unknown relevant mechanism that generates this pattern. An investigative kind concept is associated with a search for the basis of this kind. A specific hypothesis about the nature of this basis might exist and motivate the introduction of an investigative kind concept and guide scientific research. A full theoretical account of the investigative kind can only be given after appropriate empirical study and might reveal a variety of complications. An investigative kind concept may change its reference throughout scientific investigation. In addition, the study might reveal that the group of entities cannot be considered an investigative kind at all, in which case the concept is likely to be abandoned. Objects originally assumed to belong to the extension may prove not to be members of the kind. If it becomes clear that there are several relevant mechanisms that account to some extent for the observed pattern that was important for the introduction of the term, the concept may split. In any case, an investigative kind concept goes together with a scientific search, which might be open-ended.

The (general) species concept is an investigative kind concept. The origin of the species concept is a certain perceived pattern among organisms. Despite individual differences and similarities across large groups of organisms, there seem to be groups of organisms that 
have very perspicuous similarities and form some kind of biological unit. Independent of having some definition of species, we are able to recognize species taxa to a sufficient degree of intersubjectivity. The members of a species taxon are morphologically and behaviorally very similar in comparison to other species, and species have typical ecological relationships. There is a good deal of agreement over species taxa even in a cross-cultural context (Atran 1990). It is fundamental to realize that biologists address something that might be called the 'species phenomenon'. The fact that the species concept is an investigative kind concept means that we need a theoretical account of the mechanisms or features that bring about the perceived pattern among organisms. ${ }^{i}$ Indeed, considering something as an investigative kind triggers the search for these underlying factors. It is not obvious that species are investigative kinds, because it is not clear in advance that there are biologically interesting and acceptable features that define groups of organisms that largely coincide with the taxa considered as species and account for the properties that motivated the introduction of the investigative kind concept. (It was an open question for Buffon and Lamarck whether such features exists.)

Throughout biological investigation the understanding of species and the concrete grouping of organisms into species taxa may change. For instance, empirical investigation reveals that the situation is not as simple as originally assumed. Species hybridize and the boundary between species and higher taxa is sometimes not very sharp. In addition, different concrete biological features that might overlap and intergrade might be candidates for a theoretical account of species. This is one reason why we have different species concepts. 
Some researchers focus on common descent, others on gene exchange, still others on ecological competition, while all of these factors have an influence on producing the units we call species. My account of investigative kind concepts is perfectly compatible with this situation. Different species definitions are instantiations of the same scientific search. Despite distinct perceived patterns and motivations to search for an underlying basis, different theoretical accounts might be equally plausible and important to give some understanding of the situation. Viewing the species concept as an investigative kind concept addresses my first critical questions. The investigative kind concept approach does not preclude a favorable and realistic interpretation of the history of the species concept. Even though the theoretical understanding of an investigative kind concept may change, this does not mean that in the past there was no such concept or that it was theoretically useless.

In certain cases it is legitimate to say that the fragmentation of a concept (or conceptual change in general) leads to the elimination of the original concept, or makes it at least theoretically problematic. Unlike Ereshefsky, I do not use ontological criteria, but epistemic condition for the usefulness of a concept. An investigative kind concept needs to be eliminated if two (related) conditions obtain. First, elimination of the original concept occurs if it cannot figure in theoretical generalizations as it was believed to be able. The term 'species' is used in different theoretical contexts throughout biology. However, the general species concept might in fact not be able to be part of theoretical generalizations and explanation across different branches. Instead, we might need different concrete species concepts for different groups of 
organisms or different branches or theoretical approaches in biology. For instance, talking about 'species' in the context of ecology might actually have to be a shorthand for 'ecospecies' - the general species concept and no other concrete species concept is able to yield the explanations and generalizations that are characteristic for ecological theorizing. Second, elimination of the original concept occurs if the theoretical motivation for the original species concept proves to be inadequate due to empirical findings, and the different new concepts focus on independent motivations. The theoretical role that the original concept played for biology might have to be largely abandoned and the theoretical roles of new and more adequate concepts may have hardly anything in common with the original concept. In the case of species, current concepts might be adequate for addressing and accounting for species-related issues in systematics, evolutionary biology, and ecology. But if they do not retain features of the function of the original concept or legitimatize this concept to some extent, there is no real or substantial question any longer about whether a current or proposed concept is in fact a species concept.

Let me give a concrete example to illustrate my criteria. Elimination of the general species concept would clearly be required if all concrete species concepts violated its presuppositions as radically as the phenetic species concept (which defines base operational taxonomic units). Numerical taxonomy criticized and abandoned several features of the traditional understanding of species. Species were not considered as kinds with a specific (historical) basis, and phenetic approaches accepted some items of the theoretical role of the 
species concept for classification, while trying to keep their taxonomic concepts independent of evolutionary theory. If several species concepts were the product of a critique of the traditional role of the species concept and focused on independent issues (one species concept might address ecology alone, another only evolutionary theory) then the original species concept would in fact be theoretically useless.

5. A Defense of the Species Concept. The situation under which an investigative kind concept needs to be eliminated does not obtain for the species concept. Taking a closer look at Ereshefsky's account reveals why this is the case. Ereshefsky proposes three species concepts based on three different generative mechanisms. However, this is an oversimplification of current accounts and definitions of species. Several distinct current species concepts belong to each of Ereshefsky's mechanisms. Within the interbreeding approach, for instance, we have the biological species concept, the genetic species concept, the Hennigian species concept, and the recognition species concept (using the terminology and classification of Mayden 1997). Ereshefsky does not tell us why he ignores the variety of extant species concepts rather than eliminating the terms 'biospecies', 'phylospecies', and 'ecospecies' in favor of the most prominent species concepts existing in the biological literature. A much more important point is that there is also overlap with respect to the mechanisms that bring about the units called species. Often common descent and ecological selection, as well as interbreeding are important for maintaining the coherence of a species. And because of this overlap and 
continuous transition between different evolutionary mechanisms, it is not obvious what counts as a unique and separate factor. A crucial assumption of Ereshefsky's ontological account is that there are three (at least several) mechanisms. He argues for elimination because these mechanisms are assumed to be distinct and independent. This does not fit with current species concepts. Templeton's cohesion species concept or Waples' evolutionary significant unit concept both include interbreeding and ecological competition. It is the case for many species concepts that they combine elements that Ereshefsky treats as independent mechanisms. Different generative factors partially overlap and reinforce each other. This is a problem for Ereshefsky's ontological account—-but not for my investigative account.

The same point can be discussed at the level of biological fields rather than at the level of species concepts. Ecological selection is important for ecology. However, ecology cannot ignore other mechanisms such as phylogeny and interbreeding. This is due to the fact that all these mechanisms shape the biological units—species—studied by ecology. Ecological processes are influenced by the effects of phylogeny and interbreeding. These mechanisms have an impact on the structure and ecological behavior of populations. For these reasons, it is not the case that a concrete species concept can only be used for one branch of biology-the ecological species concept (or Ereshefsky's ecospecies concept) is not just of concern for ecology. This shows that my epistemic elimination conditions are not met in the case of the species concept. Due to the overlap and reinforcement of the mechanisms generating species, the extension of different species definitions shows a good deal of overlap. The general 
species concept figures in theoretical generalizations and explanations across different branches of biology. In systematics, species are characterized by the fact that they are basal taxa. Species play an important role in evolutionary theory. Several biologists think that species are important in a sense that higher taxa are not, e.g., they are the first irreversible step in phylogenetic branching. Species are considered to react as a unit in evolution (Ghiselin 1987, Mayr 1970, Simpson 1961, Wiley 1981). They are not only brought about and modified in the course of evolution, but they also influence the way evolution proceeds. In addition, species are important theoretical entities for ecological theorizing and conservation biology nowadays. The species concept is a vital theoretical tool in studying ecological competition and biodiversity. Usually, the general species concept has an application to all these task and theories. This is a crucial argument for the importance of the species concept. If the different concrete species concepts applied only to distinct parts of biological theory, Ereshefsky would have a reason for separating these species concepts. However, it is not the case that assessing biodiversity in conservation biology can be done only with, say, the ecological species concepts and theories of speciation can only mean 'species' in the sense of the biological species concept. Instead, many biological theories and branches can live with using the term 'species' without concrete specification of a definition of species.

De Queiroz already defended the general species concept by pointing out that all concrete species concepts assume that "species are segments of population level-lineages" $(1999,53)$. This characterization is his general lineage concept of species, and other concrete 
species concepts and definitions are viewed as variants of this concept. Unlike de Queiroz, I emphasize the unifying effect of the theoretical role of the species concept. In virtue of figuring in different biological theories, the general species concept sets the standards of what counts as an adequate concrete concept or species definition. A good species concept needs to pick out species taxa, to account for the perceived pattern in nature, and to fulfill its role as a species concept in taxonomic, evolutionary, and ecological theorizing. The investigative approach to the species concept helps reveal the relation between the different concrete species concepts, on why they are species concepts, and on what makes them adequate species concepts. Given the general role of the species concept as an investigative kind concept, I have an account of why we now have better species concepts, rather than just different concepts. In addition, my approach allows for historical continuity. Both former (e.g., idealistic) and current (e.g., phylogenetic) accounts are proposed species concepts because they try to broadly account for the same thing. But former accounts were revealed to be empirically inadequate to do this job. In my view, it is important to realize that the different current species concepts are not independent creations. If one does not take into account that a general species concept motivates these definitions, one is unlikely to understand why they are advanced and whether they are adequate species concepts. The debate about various species concept does not boil down to a situation where some authors do not like it when other scientists use the term 'species' for a different concept than they do. It is a debate about the nature of species. There is (still) a real question of whether for instance the ecological species concept can really fulfill 
the role of a species concept. An ecological account may not be able to define discrete kinds, which a good species concept should do. The phenetic understanding of species was largely rejected because it disagreed with several issues that are still considered to be important for a species concept. This does not mean, however, that there can be only one legitimate account of species. The empirical situation might be such that the common theoretical role of the species concept can be played equally well by distinct concrete definitions. The on-going debate about the adequacy of proposed species concepts shows that we need a general species concept.

6. Conclusion. I argued against Ereshefsky's tenet that the species concept is theoretically useless and that it does not denote a kind. While not questioning pluralism and Ereshefsky's main arguments for it, I defended the species concept from a different perspective that uses different criteria of when a concept is useful. I argued that the general species concept is an investigative kind concept, motivated by a perceived pattern and characterized by the search for the underlying mechanisms of this pattern. The species concept figures in theories across different biological branches, and in this manner, it sets the standards for what counts as an adequate concrete species concept. I laid out conditions in which the fragmentation of a concept suggests the elimination of the original concept. However, these criteria do not apply to the species concept. The use of the term 'species concept' for one of the concrete species concepts is not just a linguistic habit that has no conceptually and theoretically interesting explanation. Instead, it is still a real question as to whether a concept is a species concept. The 
species concept is important for motivating concrete definitions of species and understanding their theoretical role. Besides this, the general species concept can figure in many theoretical accounts, as biological theories do not work with only one concrete species concept. Different mechanisms that shape the origin and coherence of species overlap and reinforce each other and thus are of concern for all branches for biology. In my view, this is reason enough for taking seriously the species concept as a theoretical concept. We are not forced to accept Ereshefsky's radical conclusion and eliminate the species concept in favor of several independent concepts. Ereshefsky's strong ontological requirement that a concept is theoretically useful only insofar as it is a category in his sense is overly restrictive. This account is not sensitive to the theoretical role that some concepts play or how concepts such as investigative kind concepts actually behave. I hope that my approach tentatively provides a way of looking at the species concept that goes beyond asking whether pluralism about species is adequate or not, or whether species are real or not. 


\section{REFERENCES}

Atran, Scott (1990) Cognitive Foundations of Natural History: Towards an Anthropology of Science. Cambridge, Cambridge University Press.

Boyd, Richard (1999), “Homeostasis, Species, and Higher Taxa”, in Robert A. Wilson (ed.), Species: New Interdisciplinary Essays, Cambridge, MA: MIT Press, 141-185.

Brigandt, Ingo (n.d.a), "Conceptual Change and the Causal Theory of Reference", manuscript.

— (n.d.b), "The Role a Concept Plays in Science - The Case of Homology", manuscript. de Queiroz, Kevin (1999), “The General Lineage Concept of Species and the Defining Properties of the Species Category", in Robert A. Wilson (ed.), Species: New Interdisciplinary Essays, Cambridge, MA: MIT Press, 49-89.

Dupré, John (1993), The Disorder of Things: Metaphysical Foundations of the Disunity of Science. Cambridge, MA: Harvard University Press.

Ereshefsky, Marc (1992), “Eliminative Pluralism”, Philosophy of Science 59: 671-690.

— (1998), "Species Pluralism and Anti-Realism", Philosophy of Science 65: 103-120.

Ghiselin, Michael T. (1987), "Species Concepts, Individuality, and Objectivity”, Biology and Philosophy 2: 127-143. 
Griffiths, Paul E. (1999), "Squaring the Circle: Investigative kinds with Historical Essences”, in Robert A. Wilson (ed.), Species: New Interdisciplinary Essays, Cambridge, MA: MIT Press, 209-228.

Hull, David L. (1987), “Genealogical Actors in Ecological Roles”, Biology and Philosophy 2: $168-183$.

Kitcher, Philip (1984), “Species”, Philosophy of Science 51: 308-333.

Mayden, Richard L. (1997), “A Hierarchy of Species Concepts: The Denouement in the Saga of the Species Problem”, in Michael F. Claridge, Hassan A. Dawah, and Michael R. Wilson (eds.), Species: The Units of Biodiversity, London: Chapman \& Hall, 381-424.

Mayr, Ernst (1970), Populations, Species, and Evolution. Cambridge, MA: Harvard University Press.

— (1987), “The Ontological Status of Species: Scientific Progress and Philosophical Terminology", Biology and Philosophy 2: 145-166.

Mishler, Brent D., and Robert N. Brandon (1987), "Individuality, Pluralism, and the Phylogenetic Species Concept", Biology and Philosophy 2: 397-414.

Mishler, Brent D., and Michael J. Donoghue (1982), “Species Concepts: A Case for Pluralism”, Systematic Zoology 31: 491-503. 
Putnam, Hilary (1975), “The Meaning of 'Meaning”, in Hilary Putnam (ed.), Mind, Language and Reality: Philosophical Papers, Volume 2, Cambridge: Cambridge University Press, 215-271.

Rosenberg, Alexander (1994), Instrumental Biology or the Disunity of Science. Chicago: University of Chicago Press.

Simpson, George G. (1961), The Principles of Animal Taxonomy. New York: Columbia University Press.

Stanford, P. Kyle (1995), "For Pluralism and Against Realism about Species", Philosophy of Science 62: 70-91.

Wiley, Edward O. (1981), Phylogenetics: The Theory and Practice of Phylogenetic Systematics. New York: Wiley \& Sons.

Wilson, Robert A. (1999), “Realism, Essence, and Kind: Resuscitating Species Essentialism?", in Robert A. Wilson (ed.), Species: New Interdisciplinary Essays, Cambridge, MA: MIT Press, 187-207. 


\section{FOOTNOTES}

${ }^{\text {i }}$ Boyd (1999), Griffiths (1999), and Wilson (1999) make some similar points. The crucial feature of my account, however, is to stress the fact that the species concept as an investigative kind concept may be subject to conceptual change based on empirical findings. Investigative kind concepts exhibit the open-endedness of scientific search. 